http://dx.doi.org/10.12795/PH.1992.v07.i01.23

\title{
EL CAMINO NARRATIVO DE BOCCACCIO
}

\author{
Nicolás Valdés
}

We are giving a brief summary of Boccaccio's early narrative work -above all, as is known, a prolongation of Dolce Stil Novo structures and themes, Dante's heritage- up to his most particular creation the decameronian novel, a wise synthesis of realism and rhetoric, which immediately found its public.

In the «cento novelle» Boccaccio combines materials reelaborated by the literaly tradition (Padoan), as he did in the preceding works, going out from precise realistic details. This fact, on one hand is connected to a empirical attitude towards the world (Salinari), on the other hand, to a rhetoric solution already close to strict formalism and eloquence humanist and the same time as the dialectical crisis and certeinlty of Dante.

«(...) maximo mercatori dedit discipulum, quem penes sex annis nil aliud egi, quam non recuperabile tempus in vacuum terere»(Boccaccio, Geneulogiae deorum gentilium libri).

Hay en Boccaccio una clara evolución artística desde una narrativa bizantina, simbólica, y a todas luces inconexa -por experimental- de la considerada «primera novela de la literatura italiana» ${ }^{1}$, hasta la sabia concentración estilística y temática de la Fiammetta. Ello es prueba fehaciente de que nos hallamos ante un autor en tensión creativa, a la búsqueda de sus propios núcleos y esquemas narrativos, de su genuina

1 S. Battagl.ta, La coscienza letteraria del medioevo (Napoli 1965), 645-57. Precisamos sin embargo con B. KöNIG el carácter unitario del Filocolo, a pesar de todos sus defectos, o por ellos precisamente: hay en la obra una misma actitud narrativa y estilística (cfr. Die Begegnung im Tempel, Hamburgo 1960, 51). 
palabra poética, en definitiva de un género narrativo nuevo: la «novella» ${ }^{2}$ o novela corta, que hundiendo, a pesar de su nombre, sus raíces en la tradición latina de un Apuleyo, entronca perfectamente con el espíritu de su tiempo, con la floreciente clase burguesa y mercantil del Otoño de la Edad Media, y de los siglos posteriores. Como en el nuestro el cine, la novella de Boccaccio triunfó plenamente ya en el Trecento porque con ella triunfaba al fin lo cotidiano, lo histórico; la Historia, con mayúscula, y las historias con minúscula: las vivencias personales y concretas volvían a la literatura, desechando la casi omnipresente alegoría del monolitismo cristiano, abandonando así profundos esquemas medievales que las habían anulado en pro de la eterna felicidad del Más Allá ${ }^{3}$ Y no ya que en la novela boccaccesca, como conoce sin duda todo lector atento del Decameron, no veamos el tradicional «romanzo» («romance», y sus análogas «romanz» y «román», en español ${ }^{4}$; «roman», en francés), de marca arturiana, el cuento fabuloso o heroico; antes al contrario se halla combinado sabiamente con la descripción de la sociedad, de sus

2 P. D. STEWART, Retorica e mimica nel Decameron e nella commedia del Cinquecento. (Florencia 1986) 7 18.

3 P. Pul. fra, Le origini, en Scrittorie idee in Italia, vol. I, (Bologna 1980) 1-3. Véanse aquí las interesantes páginas de B. GrofthUYSEN ( Petrarca e l'uomo nuovo, 215-220) sobre la ruptura que supuso Petrarca, al referir alguien por vez primera su vida a través de sí mismo, con los profundos valores de los largos siglos del Medievo cristiano, que concebía la biografía de cada ser humano sólo en su relación con Dios y en con el común destino de sus congéneres. A este respecto el «Nessuno vive da sé, nessuno muore da sé» de que habla Groethuysen (215) nos lleva por ejemplo en el plano poético a «la coralidad de la amistad» apuntada por G. Contıni [ «Dante lirico», en Carlo Salinari (ed.), Antologia della critica dantesca, (Bari 1970)17-23] del Dolce Stil precedente, y se tiene así una perspectiva adecuada del trascendental significado del lírico aretino. Nadie desde luego como DANTE AlighiER había resumido a la perfección, en un sincretismo peculiar, la visión providencialista de la historia vigente en la Edad Media -y que se apunta también, por otra parte, en las primeras páginas del Filocolo boccaccesco-. Según ésta, los clásicos habrían preparado la llegada de Cristo; la Roma de los césares se habría de convertir luego en la Roma de los papas. El Virgilio dantesco es, en este sentido, revelador. Considerado mago, adivino, profeta de la inminente venida de Cristo, a lo largo de la Edad Media -obligado el recuerdo del clásico ochocentista Virgilio nel Medioevo, de D. Comparetti-, es asumido por Dante asimismo en un plano histórico-político: el descenso de Eneas a los infiernos de la Eneida (libro VI) habría sido, desde la perspectiva providencialista medieval, un hecho histórico determinado por Dios [cfr., P. Cataldi-R. Luperini (eds.), La Divina Commedia (Florencia1989), XXXIII]. Del providencialismo de la historia, o, más propiamente, de la negación de la historia, emana, por otra parte, la célebre concepción figural de Erich Auerbach, una de las aportaciones más decisivas de la crítica novecentista a la exégesis de la Comedia [en alemán, Dante als poeta der irdischen Welt, 1929; fragmentos de interés en su traducción al italiano en Antologia della critica dantesca, cit., 99-109. Otra aportación sobre el sentido figural nos ofrece H. LAUSBERG, Manual de retórica literaria, II (Madrid 1967) 288-90].

Con el sentido que tenía antes de Santillana -narración en prosa o verso, testimoniado en diferentes lugares»-, aunque, por lo que parece, el mismo Marqués también a este tipo de romance alude en su Prohemio al Condestable de Portugal cuando define, de modo peculiar, los tres estilos tradicionales. Juan de Mena, por su parte, asimila cantar a romance como relatos cultos, mitológicos [FRANCISCO LóPEZ ESTRADA (ed.), Las poéticas castellanas de la Edad Media (Madrid 1984) 56 y 107-8]. Con iluminantes palabras se refiere A. DeyERmond al tipo narrativo más peculiar del periodo medieval, subrayando la conveniencia de no confundirlo con la novela, que por nuestros pagos ha monopolizado casi toda la gama del género narrativo [ «Libros de caballerías y novela sentimental», en F. RICo (ed.) Historia y crítica dela literatura española, I, (Barcelona 1980), 352-3 y sgts.]. En general para la polisemia del término, cf., F. LÓPE:. EsTradA, Introducción a la literatura medieval (Madrid 1983 5 ). 429-33. 
caracteres, del individuo particular, en función siempre además de la aventura. Es un modelo narrativo no superado, que huye de tipologías abstractas y simbólicas de la Edad Media, que, en palabras de Hans-Jörg Neuschäfer, se resiste a la estrechez de una definición precisa («in die Enge einer Definition») e históricamente se explica por la confluencia en él de diferentes pequeños géneros narrativos del Medievo romance, aunque también de la Antigüedad y de Oriente ${ }^{5}$. El mismo Boccaccio fue plenamente consciente de la polivalencia de su proyecto narrativo, de lo que éste tenía de recogida de diferentes tipos de relatos tradicionales al señalárnoslo en el Proemio: «(...) intendo di raccontare cento novelle, o favole o parabole o istorie che dire le vogliamo» ${ }^{6}$. La novella decameroniana anticipa la novela moderna en la convergencia de elementos fantásticos e históricos, como perfectamente se ha encargado nuestra tradición castellana de reflejar con la adaptación del término «novela» (y sus derivados «novelar», «novelista», «novelesco», «novelero», etc.), para denominar, casi por antonomasia diríamos, al género narrativo. Todo un justo e indirecto homenaje, nos parece, al autor del Decameron, que parte de las Novelas ejemplares, en cuyo prólogo Cervantes («nuestro español Bocacio» como lo quiso Tirso de Molina ${ }^{7}$ ), declara su orgullo de ser «el primero que [ha] novelado en lengua castellana»" ${ }^{8}$. El éxito enorme del género novelístico se puede constatar, no sólo cn España, en toda Europa. Más inmediato que aquí lo vemos en Chaucer, en Marguerite de Navarra y, por supuesto, en todos los «novellieri» italianos del Renacimiento, desde Franco Sacchetti a Matteo Bandello o Sebastiano Erizzo. Esta transcendencia del modelo narrativo boccacciano, comparable sólo a la de Petrarca en la poesía lírica, nos las resumen las arduas palabras de Andrea Battistini e Ezio Raimondi:

«Se (...) il Boccaccio lascia agli epigoni un quadro potentemente semplificato e armonico della grande varietà del potenziale narrativo interno al medioevo, rimosso in prospettiva dal paradigma del suo capolavoro, la polifonia della novella, con l'elasticità del suo nucleo conchiuso e breve, suscettibile sempre di una lettura discontinua, si trasfonde nel Decameron, contiguo anche per questo al sublime museo mistilineo della Commedia»".

` Boccaccio und der Beginn der Novelle. Strukturender Kurzerzählungaufder Schwellezwischen Mittelalter und Neuzeit (München 1969) 7-11. El alemán enumera los subgéneros narrativos que confluyen en Boccaccio [«(...) Exemplum, Fabliau, Legende, Mirakel, Lai, Vida, altprovenzalische Nova, (...) schliesslich die verschiedenen Formen der mittelalterlichen Liebeskasuistik»] para más adelante (49) poner de relieve las diferencias entre los géneros narrativos antiguos, sin apenas complejidad, y la novela decameroniana, problemática, esto es, mucho más rica en situaciones y en el desarrollo de los personajes.

- Decameron, V. Branca (ed), (Torino 1980) 8-9. Véase la iluminante nota del editor sobre cómo han de entenderse estos términos, así como las palabras de C. Muscetra [Giovanni Boccaccio (Bari 1972) 305] acerca de la tripartición fabula, historia argumentum, ya presente en Juan de Garlandia.

? L. PANCORBO, «Nota introductiva sobre` Bocacio medieval'», en V. BranCA, Bocacio y su época (Madrid 1975), 11.

* No obstante la apreciación cervantina, en CORominas-PASCUAI, DCECH (Madrid, 1989) IV, 246, se señala que el término aparece documentado ya en 1439-40 en el Siervo libre de amor de Rodriguez de la Cámara, mientras Nebrija lo define después «novela o conseja para contar: fábula».

'Letteratura italiana. Le forme del testo. I. Teoria e poesia, vol.3, (Torino 1984) 48. 
El conjunto de cuentos de Boccaccio, como ya en buena medida se ha apuntado, constituye un modelo de «narrazione vivace con un saldo intreccio, una dinamica inventiva attraente e uno scavo psicologico dei personaggi, pur sempre in funzione dell'avventura ${ }^{10}$. Para llegar hasta ahí, sin embargo, hubieron de madurar todos esos fermentos dispersos en las obras juveniles, caracterizadas en su conjunto por la extensión de los temas y núcleos estilísticos de derivación dolcestilnovista, una intensa personal, y literaria educación sentimental que el propio Boccaccio quiso, persuasivamente, blandir donde debía, en el Proemio del Decameron:

«Per ciò che, dalla mia prima giovinezza infino a questo tempo oltre modo essendo stato acceso d'altissimo e nobile amore (...) quantunque appo coloro che discreti erano e alla cui notizia pervenne io ne fossi lodato e da molto più reputato $(. .).)^{11}$.

Consustancial, por otro lado, al temperamento artístico de Giovanni Boccaccio es la narración, sus omnipresentes deseos de contar. Motivos ha encontrado por ello la crítica para hablar, incluso, de amplios ecos de los esquemas narrativos decameronianos en la fase humanista, y en los textos en torno a Dante, carentes en buena medida del rigor fiłológico de un Petrarca, pero proclives a la anécdota, a unas tradiciones orales y populares conservadas sólo gracias al padre de la prosa italiana ${ }^{12}$.

Característico de Boccaccio había sido, en efecto, desde las primeras obras napolitanas, su gran receptividad ${ }^{13}$ hacia las más variadas fuentes: las leyendas francesas, la antigüedad clásica (con préstamos que, aunque valiosos en su dimensión concreta, hoy, desde una óptica «moderna», resultan a menudo sofocantes), la literatura mediolatina, Dante y el Dolce Stil Novo. Lo más genuino quizás -verdadera constante hasta la obra cumbre- lo constituyen los buceos psicológicos en los personajes, el repliegue elegíaco y sentimental, y al mismo tiempo, sin entrar en colisión con lo anterior, la lenta y paulatina conquista de la realidad, la «actualización» de la anécdota, que se hace evidente en el paso del Filocolo a la Fiammetta y de ésta al Decameron., donde hallamos además una dimensión nueva -los clásicos mediantes- de la naturaleza en la descripción del jardín de la

10 A. Marchest, Dizionario di retorica e di stilistica, (Milano 1978) 222. Para el concepto medieval de "romanzo", véanse las pp. 269-70.

1 Citamos de la edición de A. E. Quagi.10, 2 vols., Milán, 1980.

12 Cfr. FranchSC) Bruns, Boccaccio. L'invenzione della letteratura mezzana (Bologna, 1990) 467 y n. 85 , donde se señalan las palabras de nuestro escritor en el Truttatello acerca de los siete cantos infernales compuestos por Dante supuestamente antes del exilio. Cfr. también Giorgio PAD()AN, Il Boccaccio, le Muse, il Parnaso e l' Arno, (Firenze 1978) 232 y 241.

13 «(...) con maggior entusiasmo che precisione(...) Ma una tale accusa (...) muove da un punto di vista unilaterale, se dimentica che il Boccaccio, a differenza del Petrarca, già in quel tempo maestro del suo secolo, pare, tanto più inizialmnete, estraneo per vocazione a siffatte preoccupazioni, volto a narrare, non a documentare; che ì poi il segno del romanziere d'istinto» (Antonio Enzo Quaglio, Valerio Massimo e il Filocolo di Giovanni Boccacio, en Cultura Neolatina, Anno XX (1960), Fasc. 1, pp. 45-77. Espec. p.46 ( $\mathrm{y} n .2)$. 
introducción en el que se refugian los jóvenes protagonistas huyendo de la pestilencia, de la muerte ${ }^{14}$. Aunque no creemos oportuno en esta sede ahondar en detalles, digamos sólo que esta naturaleza inicial, un tanto al margen ya de los habituales sentidos alegóricos, es ciertamente algo decisivo puesto que equivale a dar una respuesta convincente (cabría decir mejor, verdadera) al conocido descrédito de la poesía durante el periodo medieval; como se sabe, desde los momentos fundacionales del cristianismo, y la paulatina cristianización de los clásicos antiguos (se fueron dejando de lado de este modo entonces las concepciones estéticas de Aristóteles y Cicerón, muy respetados por otra parte) la pocsía había sido juzgada ocupación frívola e inculta; en consecuencia, y de acuerdo con su subordinación al mensaje cristiano, la poesía, y en particular la representación en ella de la naturaleza durante el período medieval (verbigratia, la poesía cosmológica de Alain de Lille en el s. XII), se hallan cargadas de unos sentidos alegórico y simbólico ${ }^{15}$. Resulta así que, como casi siempre que se habla de aspectos novedosos del hecho artístico en nuestro trecentista, es obligada la referencia al íntimo amigo, pater et magister, a Francesco Petrarca. También en ese paisaje de Vaucluse y sus alrededores que recorre las Rime sparse -y que iba a trazar el devenir de la poesía lírica europea- hallamos un sentimiento y un tratamiento de la naturaleza que, se ha dicho, «están lejos de ser temas puramente literarios» y emanan de una solitaria inmersión objetiva en ella ${ }^{16}$.

El camino literario de Boccaccio desde la exégesis se recorre obviamente mejor en sentido opuesto. Si leemos detenidamente uno de los cuentos del Decameron que anosotros nos parece más logrado [y significativo, en último término, para valorar la posición última

14 Véase a este respecto, un título significativo de Mario Marti (que nosotros hemos consultado como Introduzione a Boccaccio, Opere minori in volgare (Milán 1972): Conformismo retoricoe reazioni realistiche nella disponibilità culturale del Boccaccio tra Napoli e Firenze, en Dante Boccaccio Leopardi. Studi, Nápoles, Liguori, 1980, pp. 147-88. Aunque, bien es cierto, la complejidad de este proceso hasta la síntesis decameroniana difícilmente puede ser traducida en un epígrafe: en verdad, en el periodo florentino realismo y retórica no se hallan enfrentados prácticamente como demuestra la elocuente magnificencia de la Fiammetta, protagonista contemporánea.

Lo que RugGiteRO STHANHI1, por otra parte, denomina cociente de verdad-«l'indice di credibilità della sua visione [ del artista] del mondo sub ratione pulchrip-, que es como debe entenderse la interpretación estética medieval, es asumido significativamente por Boccaccio en el mismo Decumeròn para hablarnos de Gıтtт): «ebbe uno genio di tanta eccellenzia che niuna cosa dà la natura (...) che egli con lo stile e con la penna o col pennello non dipignessse sì simile a quella..." (VI, 5). La naturaleza, como potentia es el punto de referencia utilizado generalmente por el creador medieval, y Boccaccio sigue ese criterio de fidelidad aunque, «così emblematicamente rispettato (...) nell' ouverture del romanzo, viene da lui applicato a un livello più profondo del solito, ancorchè disimpegnato da obblighi teologici-allegorici e ricondotto ad una ottica rigorosamente realistica» (Boccaccio e la poesia, Napoli 1980)132-142. Sobre la función ideológica de la naturaleza del jardín inicial, cfr. MIRKo Br-VII ACQUA, L'ideologia letteraria del Decameron y, en concreto, el cap. Il giardino come struttura ideologico-formale del Decameron (Roma 1978), 65 y sgts.

is Ibidem, pp.13-4. Cfr, también, ERnst Romirt Curtus, Letteratura della letteratura, Saggi critici a cura di Lea Ritter Santini (Bologna 1984) 327-345: véase aaquí el análisis de las posiciones estéticas, paradójicas, del tomismo (pp.337-8), y también UmB:RTo Eco, Sviluppo dell' estetica medievale, en Momenti e problemi di storia dell' estetica, I (Milán, 1978) 115-229.

th NiCHol.As ManN, Introducción al Cancionero, 2 vols., Jacobo Cortines ed., ( Madrid 1989) 57. 
de Boccaccio, por la singular simpatía -entiéndase, complicidad- que muestra con la protagonista ${ }^{17}$ ], Lisabetta e $i$ suoi fratelli (IV, 5), no nos puede ser ajena la precedente Fiammetta. Y no ya tanto, como se ha dicho no se quicre aquí entrar en polémica-, porque nos hallemos ante un personaje elegíaco (Branca) o no (Muscetta), sino porque los intimos penares de Lisabetta, y sus silencios ante las humillaciones de que es objeto por parte de sus hermanos mercaderes, saben del lagrimar «elegíaco» de Fiammetta, protagonista contemporánea, burguesa, como ella. Las dos son personajes de la realidad trecentesca, las dos sufren, son, de algún modo, nuevas víctimas del amor-dolor cortesano; una lo hace calladamente, la otra hablando de principio a fin, tal como Cesare Segre, en un agudo comentario que tituló expresivamente I silenzi di Lisabetta, hablando de la magistral sabiduría narrativa -consciencia creativa- de Boccaccio, supo advertir: «Maestro della parola(...), domina anche la più difficile eloquenza del silenzio» ${ }^{18}$. Son, en realidad, frente a frente, las dos posibilidades retóricas a que se enfrentaba Boccaccio en su habitual discurso (repetido en las páginas iniciales de su obra principal) a las infelices mujeres que son víctimas de la pasión amorosa; nos lo ha señalado Renato Barilli' ${ }^{19}$, quien, sin embargo (ignorando, a lo que parece, a la citada Lisabetta o, también a esa otra discreta heroina, de profunda vida interior, Griselda $\left.-X, 10-{ }^{20}\right)$, apunta que el narrador toscano opta al fin por la amplia elocuencia, por la generosa efusión sentimental, por, en definitiva, la «solución-Fiammetta». El mismo Barilli, al indicar tradicionales valoraciones de la Elegia di Madonna Fiammetta, que sin embargo se hacían desde un punto de vista «moderno», o considerando la obra en un plano autónomo, es decir, como algo desligado y diferente de las novelle, termina por indicarnos lo erróneo de dichos planteamientos -y esto es algo que, como se deduce de lo ya expuesto, compartimos plenamente-y la necesidad de «giudicarla anzi come una specie di prova generale delle analoghe prestazioni poi ricorrenti nel Decamerone» ${ }^{21}$. Es, pues, la de Boccaccio una

17 Carios Sai inari, en Achille Tartaro, Boccaccio (Palermo 1981) 299-303.

18 En Baratto-Serpieri-Segre-Nencioni-Cirese, Il testo moltiplicato-Letturadi una novella del «Decameron »(Parma 1982) 75-85.

19. La retoricanella narrativa del Boccaccio. L' Elegia di Madoma Fiammetta", en Quadernid italianistica, volumen VI, $\mathrm{n}^{\circ} 2$ 2, 1985, pp. 241-8; espec. 242-3. Recoge la significativa opinión. desde la verosimilitud aristotélica, de LUIovico CAST7I.vkTRo) (1505-81) sobre la desmesurada facundia de las heroinas del Decameron. Véase a este propósito también Bice Mortara Garavelli, Mumuale di retorica (Milano 1988) 47, donde además se nos indica la importancia profética del aristotelismo de Castelvetro respecto al clasicismo francés, y consecuentemente el progresivo deterioro del magnífico discurso boccaccesco -una decadencia, por cierto, razonada por BARII I cit. passim - a partir de la ruptura «del grande circuito oraleaurale», tal cual en la retórica primigenia a partir de Gutenberg.

En otra sede, Retorica (Milano 1979) 83-4. BARII.t. es tal vez aún más claro sobre las motivaciones persuasivas de Boccaccio: «(...) seguiva la sua impostazione che era di rendere eloquenti i tremori muti per timidezza e incapacità discorsiva delle povere fanciulle: per lui non c'era ombra di dubbio che il poetaoratore dovesse istruire con un massimo di eloquenza la tempesta emozionale provata dalla sua creatura»; tenemos así un Boccaccio, según el crítico, enfrentado retóricamente a grandes novelistas del XIX, a un Manzoni o a un Flaubert.

20. Giorgio Paixian, cit., 243.

21 La retorica nella narrativa di Boccacio.... cit.. 244. 
línea de maduración creativa que tiene por coordenadas la persistente disciplina retórica, una marcada entonación elegíaca y, en fin, la progresiva apertura a la realidad, que, por más que se haya pretendido, nada o casi nada tiene que ver con el supuesto realismo ochocentista de la cámara fotográfica. Y así, con agudeza, lo ha visto también Giorgio Padoàn: partiendo de precisos detalles topográficos, por ejemplo, Boccaccio «monta» los materiales oportunamente reclaborados por la tradición literaria ${ }^{22}$.Y sí, en efecto este realismo suyo guarda relación, haciéndonos eco de precisas palabras de Carlo Salinari ${ }^{23}$, con una objetividad que es una actitud empírica ante el mundo y signo indudable de libertad intelectual y reverso positivo de la profunda crisis del siglo XIV, que se muestra también en el inseguro paso del Comune a la Signoria, en la melancólica actitud de los autores «menores» o en el hundimiento de las grandes catedrales de ideas a manos de la filosofía humanista. Parece lógico que sobre este fondo crítico de «un siglo de transición» en que no sólo son removidos los cimientos de las dos grandes instituciones, Imperio e Iglesia, sino que afecta también a quiebras en grandes compañías mercantiles (la de los Bardi, por ejemplo, para la que trabajaba el padre de Boccaccio), el nuevo género de la novella boccaccesca, al mismo tiempo legendario e histórico, donde se exhiben los prejuicios y mezquinos intereses de la nueva clase, hallase de inmediato «su» público. De suerte tal que incluso con ansia y con pasión, intercambiándoselas o robándosclas unos a otros, fueron leídas por sus contemporáneos las primeras copias de la obra maestra de messer Giovanni: toda una comunión con ese público mercantil florentino que, por su condición viajera, sería decisivo para su fortuna curopea ${ }^{24}$.

2 PADOAN, cit, 123-146.

2.4 «(...) non è possibile rintracciare un preciso criterio di scelta e di giudizio, un punto di vista fermo dal quale valutare quella molteplicità, una sicura concezione del mondo(...) Boccaccio ha verso le cose un atteggiamento empirico: ciò che si trova nella realtà è oggetto sempre della sua attenzione e solo in qualche caso del suo giudizion-C. Salinari (en A. Tartaro, cit., 300): apoya su argumentación en el acaso-limite» di Lisabetta al ser, como se dijo arriba, un ejemplo de participación íntima y apasionada del autor en los hechos narrados que sin embargo no incide en la exposición objetiva de la historia-.

Reflejo indudable de la crisis del siglo, la actitud contradictoria de Boccaccio (hombre sin precisas ideas políticas, tal como nos lo presenta Giorgio Padoan) respecto al ideal aristocrático-caballeresco (evidente en la X jornada) y una, por otra parte, sensibilidad artistica burguesa que le lleva a simpatizar con personajes populares irreverentes, burlescos. De modo tal que en el Decameròn acentúa la fuerza cómica del relato una matcria como el adulterio, antes (excepción hecha de la Ficammetta) sólo teorizada (De Amore) y casi rechazada en el Filocolo. Las palabras de Padoan corroboran, sin duda, Ias citadas de Salinari sobre la posición empirica de Boccaccio, al apuntarnos, en otro lugar, «l'estrema libertà dello scrittore nei riguardi della religione»: constantemente considerado irreligioso, en el Decameròn «si rivela intimamente credente» (cit., respectivamente, 63-6 y 54-5).

24 Vitrori: Branca, Boccaccio medievale (Firenze 1975) 3-6. Al éxito del Decameròn entre los miembros de la nueva clase se refiere también Christian Bec: «la grande majorité des possesseurs-lecteurs de manuscrits de Boccace appartiennent à cette haute bourgeoisie marchande qui gouverne Florence sans partage de 1382 à 1434» (Studi sul Boccaccio, vol. IX (1975-6) 250). Por otra parte, el primer Boccaccio conocido en España es grosso modo el moralista pero ya hay ocho noticias de textos del Decamerìn en las bibliotecas catalanas durante el periodo 1484-1509 -David Romano, «Il Decameron nelle Biblioteche Catalane», Cultura meridionale e Letteratura italiana (Napoli 1982) 101-5. 
Hasta el Decameron, que cierra nítidamente según la crítica tradicional toda una etapa, el recorrido ha sido largo, fecundo en experiencias literarias que, aisladas, desde una perspectiva moderna, no siempre tal vez nos parecen afortunadas. El Boccaccio del Filocolo, por cjemplo (como también el del Filostrato o la Teseida, aunque el verso narrativo de la octava real no sea de nuestro interés aquí), es un narrador dispersivo, como se dijo al inicio: narra los azarosos amores de Florio y Biancifiore pero diluye el argumento central con la presencia de mil nuevos personaje y episodios, ficticios o pseudoautobiográficos, sobre todo con la ayuda de una masiva contaminación clasicista que se cimenta en las leyendas ovidianas y en la anecdótica de Valerio Máximo. La realidad contemporánea se halla sólo en estos paréntesis tomados por autobiográficos (prólogos y epílogos, habitualmente), los cuales perfilan la imagen del narrador que se proyecta a su vez en la imagen de su héroe, enclavado éste en ambientes remotos. Es lo que ha sido denominado los dos niveles de la ficción ${ }^{25}$ presentes en Filocolo, Filostrato y Teseida de derivación dantesca - la Vita Nuova, al fondo- aunque aquí, obviamente, a priori y fuera de los esquemas del prosimetrum. Boccaccio se inventa su propia aventura amorosa, perfecta vie romancée en torno al mito de Fiammetta que ha sido interpretada como autobiográfica hasta tiempo no lejano desde los de la crítica romántico-positivista, la misma crítica que veía en Boccaccio la encarnación del hombre nuevo, un preludio del Renacimiento... y no sólo cuando de cuestiones estríctamente religiosas se trataba ${ }^{26}$.

La pseudo-autobiografía, esa imagen sublimada que construyó de sí, con alusiones a la vida napolitana y florentina del tiempo, va encajando cual piezas sueltas de un puzzle en la complementariedad recíproca de algunas de las obras juveniles (Filocolo y Teseida) ${ }^{27}$ y dejando un tanto al margen el singular tratamiento de la misma en la Elegia di Madonna Fiammetta-inversión de papeles respecto al tradicional juego amoroso ${ }^{28}$, concentración de esquemas líricos, que significan al mismo tiempo actualización de la anécdota, etc.y la supervivencia, entre otros, de Fiammetta y Panfilo ${ }^{21}$ en el Decameròn. Persisten todavía en circulación páginas, de edición vieja o reciente, que presentan un Boccaccio

25 Giulia Natali, Progetti narrativi e tradizione lirica in Boccaccio en Rassegna della letteratura ifaliana. anno 90, $\mathrm{n}^{\circ} 3$, (1986)384-85. Para mayor información sobre los elementos autobiográficos del arte de Boccaccio, véase Sal.Vatori: Battagi.1a, cit., 615-7 y Francesco Bruni, cit., 210-217.

26. FrancF.SCo DF: SANctis (en Tartaro, cit., 252): «Ser Ciapperello è un Tartufo anticipato di parecchi secoli (...) Giovanni Boccaccio sotto un certo aspetto fu il Voltaire del secolo decimoquarto".

Para calibrar estas afirmaciones de Dı. SANCTIS, nada mejor que consultar las artes dictaminis duecentescas, entre ellas, las cartas-modelo de la Rhetorica antigua de Boncompagno da Signa, donde, tal como documenta RoBFRT L. BFNSON, ya hallamos notables testimonios de sátira de los eclesiásticos y de sus amores -Protohumanismand Narrative Techique in Early Thirteenth-Century Itulian «Ars Dictaminis» en, CottinoJones y Tuttle, (eds.), Boccaccio: Secoli di vita, (Ravenna 1977) 31-50-.

27 Giulia Natal., cit., 395.

28 Que algunos, ignorando su verdadero significado, han considerado "che non va preso troppo sul serio" ( $S$. Painter, citado en Graziano Ruffini, De amore -Introduzione- (Milano 1980) XX)).

29 No de modo casual es el joven de la «onesta brigata» a quien Boccaccio asigna la tarea de reproducir «la serietà dei suoi interessi ideali» $y$, por este motivo, además le hace rey de la fundamental última jornada (C. Muscetta, Boccaccio (Roma-Bari 1986) 284)). 
nacido en París, de una noble parisina, que más tarde sedujo a Maria d'Aquino, hija del rey de Nápoles, etc, etc. que muy a menudo se interponen como barreras casi infranqueables en la normal tarea docente ${ }^{30}$.

Los anatopismos y anacronismos, los calcos ostentosos del alto paradigma de esta narrativa juvenil, Ovidio, las variadas experiencias, en fin, en los géneros (sin ovidar aquí los dictamina y las versiones de Tito Livio), convergen, sin colisión, en lo que sería una especie de poligénesis personal, en el Decameròn. Así se encarga, en efecto, de subrayarlo la crítica más avisada (Slovskij, Contini, Segre, Branca...): las grandes líneas estructurales y estilísticas, los mismos temas in nuce -con excepción quizás del peso mitológico; ahora, diríamos generalizando, el mundo contemporáneo-, incluso la poesía juvenil, convergen con maestría en las «Cento Novelle». Particularmente feliz se revela, por ejemplo, el célebre episodio de las Questioni d'Amore (Filocolo., IV), elegante juego de entretenimiento típico de la sociedad cortés, recreado del De Amore de El Capellán y que tuvo éxito autómono tanto en las letras italianas como en las castellanas, aquí por la traducción -y sus tres ediciones del s. XVI- de Diego López de Ayala, canónico de Toledo ${ }^{31}$. Este paréntesis en la narración de la aventura de amor de Florio y Biancifiore, derivado del naufragio de Filocolo en el puerto de Nápoles, se considera precedente «embrione» (Rajna)- de la cornice decameroniana, puesto que tenemos ya de algún modo a la brigata que para cobijarse de los calores estivales propone debates de ética amorosa, eligiendo por «reina» a la misma Fiammetta, de quien se enamora un tal Caleòn, imagen de Boccaccio ${ }^{32}$. Como se ha indicado arriba, Fiammetta y Panfilo, a quien podríamos considerar, en lugar de Caleòn, imagen del autor (ya porque es quien se

30 Bt:RNhARI) Kónici se quejaba amargamente (con toda razón, en efecto, tras los decisivos trabajos previos de BHI andevich o del propio Branca) de la persistente vigencia de la interpretación biográfica de Boccaccio desde esquemas propios de un realismo siglo XIX (Die Begegnung im Tempel, cit., 22-23 y sgts.).

" He aquí los extremos tipográficos:

- Con el título ambiguo de Laberinto de Amor. Sevilla, 1546, AnIRís IfF Burgos.

- Treze questiones muy graciosas sacadas de Philoculo del famoso Juan Bocacio. Toledo, 1549, JuAN DI: AYAL.A.

- Treze questiones, como parte integrante del volumen Question de amor, de dos enamorados, Venezia, 1554, Gabril. Gi(n.ITU) de. Farrarils.

Cfr. J. BI AnCo Jimint:z, Le opere di Giovanni Boccaccio in Spagna nel "400 e "500: una prima valutazione bibliografica, en Miscellanea Storica della Valdelsa, Anno LXXXIII. N.1 (1977) 3-20.

¿Qué es la citada Question de amor de dos enamorados? Entre esa literatura de salón (en palabras de Migliorini) yue dominó el panorama de la del siglo XVI, tuvo enorme éxito, tal como señaló BeNi:DiTT() CRoCl, una novela española. la Question de antor, de autor anónimo aunque «uno spagnolo, senza dubbio, che viveva a Napoli, nella migliore società», Ya desde el título, de claro sabor boccaccesco, fragmentaria como el Filocolo, la Question de amor constituye un vivo retrato de la sociedad hispano-napolitana de la época a través de «lettere, ragionamenti, descrizioni di feste o meglio, catalogo di vestiti e di motti, poesie. e (...)altre cose (...)». Croce reseña trece ediciones de la novela en el Cinquecento y nos indica que «cadde poi in dimenticanza, e dal 1598 non fu mai più ristampatan [Cfr. Napoli dal 1508 al 1512 -da un antico romanzo spagnuolo-, en Archivio Storico per le province napoletane, XIX ( 1894) 140-63].

12 Gianfranco Contini, Letteratura italiana delle origini (Firenze 1968) 710-11. Cfr. también MARIo PE:TRINI, Nel giardino del Boccaccio (Udine, 1986) 137 y nts. I y 2. 
encarga antes de hacerlo en la Fiammetta, ya porque reproduce como nadic los ideales corteses compartidos por el narrador), dirigen respectivas jornadas narrativas en el Decameròn. A propósito de la onesta brigata en su conjunto de la cornice, que es esencial en la estructura unitaria de los cuentos, habría que seguir hablando, en efecto, por la actualidad de la acción narrativa y por sus posiciones éticas, de prolongación dela pseudoautobiografía del escritor en su obra maestra: son de nuevo, en último análisis, los dos niveles de la fictio que hemos subrayado arriba en relación no sólo con el Filocolo, sino también con la Teseida y con el Filostrato, y fusionados posteriormente en la Fiammetta. Se trata de un primer episodio embrionario de la obra mayor. De otros ecos del primer romance en el Decameron ha tratado Mario Petrini ${ }^{33}$.

Característica de Boccaccio será la captación de la realidad multiforme, refinada y popular, de agudos contrastes, del otoño de la Edad Media; por ejemplo, en su aceptación del adulterio (Decameron) y, por contra, en su rechazo (Filocolo) como antes había hecho el mismo maestro Capellán ${ }^{34}$; o en la transgresión abierta de las clases sociales que se observa en el comportamiento de sus personajes ${ }^{35}$. Es decir, aprehende la vida por encima de lo contingente ( $\sin$ que por ello deje de ser válido el calificativo «epopea dei mercatanti» usado para las Cento Novelle ${ }^{36}$ ), «sub specie aeternitatis», diríamos ${ }^{37}$. Porque lo contingente, esa realidad de los mercaderes puesta por ejemplo es filtrada literariamente, como ornamento, en un plano esencialmente estético, desligándose de ese principio, tan medieval pero de ascendencia horaciana (el célebre miscere utile dulci del Ars poetica ${ }^{3 \kappa}$ ), de que la belleza no interesa por sí misma; el mismo marqués de Santillana, a mediados del XV, nos recordaba los viejos principios: « ¿E qué cosa es la poesía (...) syno un fingimiento de cosas útyles, cubiertas o veladas con muy fermosa cobertura

13 Ibidem., 137-144.

${ }^{3}$ PAIXAN, cit, 54 y 55 ; y G. RUHHINI, cit., XIX.

35 Guss:Pp: Chircchl, Recensioni, en Studi sul Boccaccio, vol. XII (1980), 350-1. Nadie, por otra parte, como J. Huizinga ha reflejado los contrastes agudos -de idealización y a la vez de realismo crudo, de ascetismo y de exquisito lujo en los ornamentos- de la sociedad occidental durante los ss. XIV y XV, que son anticipados en los cuentos decameronianos, en el arte decadente (como lo definió E. G. PARom ) de Boccaccio: «La última Edad Media es uno de esos periodos terminales, en que la vida cultural de los altos círculos sociales se ha convertido casi íntegramente en un juego de sociedad. La realidad es áspera, dura y cruel; por ende, se la somete al bello juego del ideal caballeresco y se edifica sobre éste el juego de la vidas -cfr.El otoño de la Edad Media, tr. de Josí Gaos, ( Madrid 1978) 111-.

Th VITTORI: BranCA, cit..

37 VIKT) SKI.ovskis (en Tartaro, opus cit., 292-3): «E sinceramente convinto [Boccaccio] che gli uomini e i costumi siano stati sempre gli stessi (...) Uomo del sorgere di una nuova epoca, il Boccaccio riteneva il suo tempo l'unico che avesse raggiunto la retta comprensione dell'esistenza».

${ }_{78}$ «I poeti aspirano a insegnare o dilettare, ad unire l'utile al dilettevole...I vecchi criticano i componimenti senza morale; i giovani superbi trascurano i componimenti austeri»-citado de RICHARI) MCKEON, La critica letteraria e il concetto dell' imituzione nell' antichità, en R. S. CRANミ) (ed.) «Figure e momenti di storia della critica» (Milano 1967) 176; y cfr. también aquí 129 en 182, donde se pone de relieve la opinión de Plutarco, contraria a la de Horacio (e interesante para entender las posiciones estéticas del Medioevo), «secondo la quale diletto ed edificazione morale sono fra loro in concorrenza»-. 
$(\ldots))^{4} \aleph^{39}$. Y de literatura pura se ha hablado a propósito de la obra maestra de Boccaccio; la realidad es encauzada en la retórica, pero -neta diferencia con Dante-con la finalidad hedonista del hecho literario, disipando «qualsiasi ombra di apostolato» ${ }^{40}$; ello le viene a nuestro narrador sin duda de su familiaridad con los clásicos antiguos (a cuyo conocimiento, nótesc, Santillana aplicaba precisamente el concepto de deleite ${ }^{41}$ ). Los personajes son a veces -nos lo señaló con penetrante inteligencia Slovskij- [tal es el caso de la novella de Tito y Gisipo $(\mathrm{X}, 8)$ ] verdaderos oradores y filósofos, que no pretenden transformar la realidad sino simplemente justificar la ponderada elocuencia de sus palabras, hasta el punto de que al final se desvanece por completo el «color local» ${ }^{42}$. Ello se acentúa, nos parece, con el «gran retorico» fray Cipolla (VI,10), que declara, en generosa perorata, haber visitado nada menos que las tierras de Truffia, Buffia y Menzogna, habitadas por clérigos que hacen honor al topónimo, no como él, evidentemente ${ }^{43}$. Esto es novedoso: vemos en Boccaccio la obra con una finalidad literaria exclusiva, lúdica,

3. Las poéticas castellanas en la Eidad Media, cit., 52; y n. 52 y 53 en 98-9. Así, por otra parte, señala Lópl:\%. ESTRAa)A, Casiodoro (s. VI), en sus Variurum libri duodec im, habia valorado la "ciencia de las letras" sobre todo por su utilidad moral: «Gloriosa est denique scientia litterarum, quia quod primum est, in homines mores purgat» (ib., p. 104). Estamos ante una concepción de la Retórica, de un primer momento de la Edad Media, al servicio de la elocuencia sacra; el mismo Casiodoro en su Expositio in Psulterium subraya que el cristianismo necesita de las artes liberales si quiere llegar a todos los hombres (cfr. McKi:ox, cit., 199 y n. $52 \mathrm{en} \mathrm{222).}$

Parece claro que en este concepto de la utilitas de nuestros prehumanistas se advierte un revelador y conocido desfase filológico respecto al rigor textual, de la palabra en su valor estético, de un Bruni, de un Manetti, de un Salutati. Como no es el caso de entrar aquí en demasiadas profundidades, apuntemos sólo que de este asunto trata con clarividencia P. Russi-1. -Traducciones y traductores en la Península Ibérica (1 400-1550), (Barcelona 1985) passim- al poneren relación el concepto y método literales de la traducción frecuentes por nuestros pagos a lo largo del s. XV, y sobre la base de una pertinaz interpretación cristiana de los «auctores» a partir de San Jerónimo y su De optimo genere interpretandi. Una excepción, aunque con matices, vino a ser El Tostado (en su Comento de Eusebio de 1506) quien, preocupado por una interpretación ad sententiam, por la clocuencia y por equiparar la lengua romance a la latina (obsérvese que Santillana concibe el grado sublime sólo en relación estrecha con la lengua griega e latyna ), advierte, consciente de que cada lengua posee sus peculiaridades, que un buen traductor ha de trasladar la "fermosura» del original. Como es bien sabido, el verdadero cambio de orientación en la tarea traductora. lo señaló JuAN BosCÁx en su versión de /l Cortegiano, elogiada por GARCI ASo y considerada «un verdadero manifiesto de la nueva corriente "(cfr. LAPtSA, Historia de la lengua española (Madrid 1981 9) 303-4. L. Russo, en Tartaro, cit., 275-7.

41 Claro que, habiendo arraigado profundamente en España la semilla de la Escolástica, de la lectura de los antiguos nulo agrado a alguno de sus contemporáneos le parecía que pudiera desprenderse: «Despláceme cuando veo tender a aquel estilo antiguo, gentil o pagano, e con grande stilo inquerir aquellas oraciones e viejos tractados que ficieron los griegos e aun los romanos antes que la sancta fee rescibiesen (...)", afirma Al.HNSO DI: CARTAGi:NA, humanista a pesar de todo por haher romanceado la retórica de Cicerón. Con CARTAGI-NA polemizó (célebres, como se sabe, las disputas nacionalistas en los albores del Renacimiento) LE(NARIX) BRUNI que lo consideraba -aunque «iuris professor eximius..., magnis occupationibus regiis occupatus"- hombre negado para el griego y las humanae litterae -cfr. F. Rico, Las letras latinas del siglo XII en Galicia, León y Castilla, en Abaco, Estudios sobre literatura española, II (Madrid 1969), 90 y $91-$

42 Si.ovsku, cit.

43 Ed. cit., 562-3. 
precisamente porque late en él, como en Petrarca, el espíritu más auténtico del paganismo que los largos siglos medievales habían en buena medida proscrito al considerar la poesía ciencia menor, insincera; hay en el narrador certaldés, pues, desde esta nueva dimensión estética, una considerable distancia (que parecería mayor de lo que representa el medio siglo) con respecto a Dante y a los esquemas de la Escolástica, aun cuando, Curtius dejó bien sentado (con E. Gilson ) que «Il tomismo di Dante è un mito distrutto», por otro lado, «che è il primo tra i Moderni a riunirsi ai grandi classici dell'antichità» ${ }^{44}$. Lo vemos inventando incluso, según apreciación de Mario Baratto, un lenguaje teatral contemporáneo, hecho éste que justifica su influjo determinante en la comedia italiana del XIV ${ }^{45}$. Hay una sensibilidad hacia lo multiforme que se resuelve en una actitud con mucho ya del individualismo humanista, del autoconocimiento, de la vida estimada a partir de la vida misma, no ya anulada en la medieval relación con Dios y con los demás ; y si no oígamos a su alter ego Panfilo en la conclusión de la novena jornada, que nos pone delante «una morale che è un preludio all'umanesimo ${ }^{46}$ :

«Ciascuna di voi pensi di ragionare sopraquesto, cioè: dichi liberalmente ovvero magnificamente alcuna cosa operasse intorno a' fatti d'amore o d'altra cosa. Queste cose e dicendo c udendo senza dubbio niuno gli animi vostri ben disposti a valorosamente adoperare accenderà: chè la vita vostra, che altro che brieve essere non puote nel mortal corpo, si perpetuerà nella laudevole fama, il che ciascuno che al ventre solamente, a guisa che le bestie fanno, non serve, dee non solamente desiderare, ma con ogni studio cercare e operare ${ }^{47}$.

Aunque, llegada la ocasión, tampoco las eluda, no hay en la obra de Boccaccio otras tomas de partido que las literarias: atentísimo, como Petrarca, a la revisión y reelaboración de los propios autógrafos, de suerte que en «certe novelle le varianti sono talmente continue che non par lecito confondere i testi, anzi sembra doveroso pubblicarli ognuno di per sè», señaló Giorgio Pasquali ${ }^{48}$. El mismo narrador supo en el Trattatello in laude di Dante precisar la distancia que le separaba de Dante en lo tocante a la participación del literato en la vida pública, algo bien decisivo si se tiene en cuenta de qué manera se hallan

44 Curtius, cit, 340. Ténganse siempre presentes no obstante tanto el alegorismo universal de los cuatro sentidos como ese propósito ético, didascálico, de partida de la iluminante epístola a Can Grande (XIII, 13) como telón de fondo para la interpretación de la Comedia: «Removere viventes de statu miseriae et perducere...." (véase en Tutte le opere, L. BI.AsucCI (ed.), (Firenze 1980) 341-52).

4 Realtà e stile nel "Decameron" (Roma 1984) 241: «il Boccaccio inventa, nel corpo del narrabile, i modi del teatrabile». Veáse también PAMH. A D. STHWART, cit, passim, y Danit-1 A Gu min, Il Boccaccio e la poesia latina francese del XII secolo, en Studi sul Boccaccio, vol. XIII (1981-82), 327-62, especialmente 344, donde se refiere el "círculo" de la comedia clásica hasta el Renacimiento: uno de los hitos en el despertar del teatro lo fue el Decameron.

4h. MuschtTa, cit., 284.

47 Ed. cit., 829-30.

48 Storia della tradizione e critica del testo (Firenze 1988) 427. Para la revisión textual en Pr:Trarca, cfr. Nichot as MANN, cit., 40-1. 
entrelazados compromiso político y obra mayor en el poeta florentino ${ }^{49}$. Estamos ante la autonomía del hecho literario, el mensaje estético por encima de todo lo demás ${ }^{50}$, que, como indica Umberto Eco ( $\mathrm{y}$ nos parece que es un asunto generalmente desconocido y que puede parecer paradójico con lo arriba expuesto) está ya recogido en la teoría estética de Sto. Tomás: «non pertinet ad laudem artificis, inquantum artifex est, qua voluntate opus faciat; sed quale sit opus quod faciat ${ }^{51} \gg$. De lo que tuvoplena consciencia el Boccaccio de la madurez como nos muestran, frente a la tradicional alegoría, su novedosa interpretación literal del divino poema ${ }^{52}$, y también en general sus palabras, de humanística defensa del hecho literario, de los dos últimos libros de las Genealogie, cuando por ejemplo nos habla sobre su vocación «ad poeticas meditationes dispositum ex utero matris».

4) BRLINI, cit., 28 y 52 .

5) Ibidem., 20-25: la ruptura (matizada, no obstante, en el narrador) de Petrarca y de Boccaccio con las disciplinas universitarias medievales, con los estudios de derecho y en general con las scientie lucrative. Esto es algo de enorme transcendencia que guarda relación con ese publico nuevo del otono medieval, alejado de las certidumbres dantescas: unos lectores a quienes ahora se deja con completa libertad de juicio. BATtISTINI y RaIMONDI (cit., 5I) a este respecto nos suministran una nota sacada del cierre del Decameron de «rilevanza in sede di poetica autointerpretativa»: "Ciascuna cosa in se medesima è buona a alcuna cosa, e male adoperata può essere nociva di molte; e così dico delle mie novelle».

5 Sviluppo dell 'estetica medievale, cit., 183 (véanse no obstante consideraciones anteriores (115-160) sobre la integración del bello y del bueno en las posiciones medievales más ascéticas de quienes, censurando la fruición estética, no dejan de reconocer su invencible atracción).

62 Clr. PADOAN, cit., 245-6. Al hablar de la alegoría, género genuinamente medieval, conviene precisar con F. BRuNi (cit., 145-7 y nts. 8 y 9) que en la obra juvenil de nuestro narrador (diferencia neta con su madurez. latina) hay ya un tratamiento novedoso del género, dado que éste no siempre se exige una correspondencia doctrinal. Es una contraposición clara con el Medievo edificante que tendría que ver-tal como nos parece a nosotros- con la célebre definición-distinción teórica dantesca (Convivio II i 3-4) de la alegoría de los poetas y de los teólogos, presente ya en los platónicos franceses del s. XII. Tal como nos dice Bruni, Ios poetas liberan a la fábula de las «rassicuranti moralizzazioni allegoriche». De la existencia en Boccaccio de una ruptura conel valor medieval de la alegoría nos hablan también BATTISTINI-RAIM(INII, cit., 50, aunque BÁrBF:RI-SQUARotTI precisa cómo debemos entender la alegoría en el Boccaccio humanista a partir sobre todo de la Genelogiae deorum gentilitm y sus diferencias con Dante (Le poetiche del Trecento in Italia. en Momenti e problemi di storia dell'estetica. cit. 319 y sgts.). 